\title{
Análise do comprometimento medular e detecção do desalinhamento postural de pacientes infantis com disrafismo espinhal
}

\author{
Analysis of spinal cord involvement and detection of postural \\ misalignment of infants with spinal dysraphism \\ Análisis del compromiso medular y detección del desalineamiento \\ postural de pacientes infantiles con disrafismo espinal
}

\author{
Thaynara do Monte MÉLO' \\ Paulo Henrique Meira DUARTE1 \\ Hellen Cristina Barbosa PEREIRA 1 \\ Natália de Fátima Meireles PEREIRA1 \\ Rielly Maria Cruz da SILVA2 \\ Nícia Farias Braga MACIEL3
}

\begin{abstract}
${ }^{1}$ Fisioterapeutas pela Faculdade Maurício de Nassau, UNINASSAU, 58030-000, João Pessoa - PB, Brasil ${ }^{2}$ Graduanda do curso de Fisioterapia da Faculdade Maurício de Nassau, UNINASSAU, 58030-000, João Pessoa - PB, Brasil ${ }^{3}$ Docente Mestre do curso de Fisioterapia da Faculdade Maurício de Nassau, UNINASSAU, 58030-000, João Pessoa - PB, Brasil
\end{abstract}

\begin{abstract}
Resumo
Introdução: Disrafismo espinhal é uma condição congênita atribuída às alterações provenientes de falhas nas estruturas que compõem o sistema nervoso central, sendo considerada como uma anomalia que impulsiona os tecidos envolvidos a um mau desenvolvimento, sujeito também à abertura e outros defeitos. Objetivo: Identificar as possíveis alterações posturais de crianças com disrafismo espinhal e correlacioná-las com os níveis de lesão medular congênita. Material e método: A planificação para esta revisão foi iniciada no mês de maio, a partir da problemática indagada pelos autores da pesquisa, cujo interesse foi averiguar quais são as alterações de ordem postural que a patologia apresenta segundo o nível de comprometimento motor. Resultados: Considerando as informações obtidas acerca dos níveis de lesão medular congênita, é importante esclarecer as suas respectivas categorias juntamente com os déficits motores que a patologia exibe em sua particularidade. Por meio de uma tabela organizacional, estudos literários, clínicos e experimentais foram expostos para discussão. Todos os autores demonstraram estar de acordo com as desordens que acometem o alinhamento biomecânico dos pacientes com espinha bífida aberta. Conclusão: O presente estudo serviu como fonte de auxílio para todos na grande busca do saber, propiciando novas investigações na área escolhida, com interesse em futuros projetos, de ordem prática.
\end{abstract}

Descritores: Disrafismo Espinal; Postura; Doenças da Medula Espinal; Anormalidades Congênitas.

\section{Abstract}

Introduction: Disrafismo spinal is a congenital condition attributed to changes arising from failures in the structures that comprise the central nervous system, being regarded as an anomaly that propels the tissues involved in a bad development, also subject to the opening and others defects. Objective: Identify possible postural changes of children with spinal disrafismo and correlate them with the levels of congenital medullary lesion. Material and method: The planning for this revision was initiated in the month of May, from the problematic inquired by the authors of the research, whose interest was to ascertain what are the changes in postural order that the pathology presents according to the level of motor compromise. Results: Considering the information obtained from the levels of congenital medullary lesion, it is important to clarify their respective categories together with the motor deficits that pathology exhibits in its particularity. Through an organizational table, literary, clinical and experimental studies have been exposed to discussion. All the authors demonstrated to be in accordance with the disorders that affect the biomechanical alignment of patients with spina bifida open. Conclusion: The present study served as a source of aid for all in the great quest for Saber, providing new investigations in the chosen area, with interest in future projects, of practical order.

Descriptors: Spinal Dysraphism; Posture; Spinal Cord Diseases; Congenital Abnormalities.

\section{Resumen}

Introducción: La disrafismo espinal es una afección congénita atribuida a los cambios derivados de fallas en las estructuras que componen el sistema nervioso central, siendo considerado como una anomalía que impulsa los tejidos implicados en un mal desarrollo, también sujeto a la apertura y otros defectos. Objetivo: Identificar posibles cambios posturales de los niños con disrafismo espinal y correlacionarlos con los niveles de lesión medular congénita. Material y método: La planificación de esta revisión se inició en el mes de mayo, a partir de la problemática investigada por los autores de la investigación, cuyo interés era determinar cuáles son los cambios en el orden postural que la patología presenta según el nivel de compromiso motor. Resultados: Considerando la información obtenida de los niveles de la lesión medular congénita, es importante clarificar sus categorías respectivas junto con los déficits del motor que la patología exhibe en su particularidad. A través de una mesa organizativa, los estudios literarios, clínicos y experimentales han sido expuestos a la discusión. Todos los autores demostraron estar de acuerdo con los desordenes que afectan la alineación biomecánica de pacientes con espina bífida abierta. Conclusión: El presente estudio sirvió como fuente de ayuda para todos en la gran búsqueda de saber, proporcionando nuevas investigaciones en el área escogida, con interés en futuros proyectos, de orden práctico.

Descriptores: Disrafia Espinal; Postura; Enfermedades de la Médula Espinal; Anomalías Congénitas.

\section{INTRODUÇÃO}

Disrafismo espinhal é uma condição congênita atribuída às alterações provenientes de falhas nas estruturas que compõem o sistema nervoso central, sendo considerada como uma anomalia que impulsiona os tecidos envolvidos a um mau desenvolvimento, sujeito também à abertura e outros defeitos ${ }^{1}$.

O desenvolvimento do sistema nervoso (SN) é formado no primeiro mês após a fecundação no embrião, precisamente entre a $3^{\mathrm{a}}$ e $4^{\mathrm{a}}$ semana. Essa evolução acontece por meio da proliferação de conjuntos de células que se dividem e se expandem. Tal processo constitui várias outras estruturas importantes para o funcionamento adequado de uma atividade neural. Em meio a tantos elementos, encontrase o tubo neural, que após atingir determinado crescimento e consequente transfiguração, o mesmo se torna responsável por originar os principais segmentos anatômicos do ser humano ${ }^{2}$

Dentre tantas imprecisões, está a mielomeningocele (MMC), patologia neurológica classificada como sendo o tipo mais habitual de disrafismo espinhal ou espinha bífida aberta. Essa malformação é decorrente de uma falha no fechamento do tubo neural e apresenta uma considerável taxa de 
incidência, com cerca de 1-1,5 por 1.000 nascimentos ${ }^{3}$.

A sintomatologia depende muito da localização e da dimensão da medula espinhal, podendo provocar diversas incapacidades permanentes e graves na criança, como problemas estruturais e fisiológicos, déficit de aprendizagem, paralisia flácida dos membros inferiores, hidrocefalia, deformações na coluna vertebral, ou ainda, impasses para erguer-se, deambular ou conter voluntariamente as atividades funcionais dos outros sistemas ${ }^{4}$.

Em relação ao aspecto motor e nível de lesão funcional está o prognóstico de marcha, ponto que deve ser nitidamente evidenciado pois está ligado ao nível de comprometimento medular. Sabe-se que quanto mais alta for a localização e extensão do trauma, pior será o prognóstico para que a criança deambule. Assim, o diagnóstico pode ser realizado ainda no interior do útero e quando comprovado, aumentamse as chances de tratamento com a devida intervenção ${ }^{5}$.

Numa avaliação em que o sinal a ser examinado é de ordem postural, a criança a ser analisada adota permanentemente o posicionamento estático. É por meio dessa estabilidade em pé que as alterações no alinho estrutural são observadas e, não havendo correção adequada podem causar disfunções musculares durante a postura dinâmica ${ }^{6}$. É importante recordar que a ação muscular está diretamente ligada a uma atividade neuromotora, pois a musculatura necessita de uma ativação fornecida pelo sistema nervoso, que por meio de suas atribuições obtém um controle neural do movimento ${ }^{7}$.

Os músculos são componentes do corpo humano responsáveis por muitas funções, dentre elas, está a capacidade de sustentação dos órgãos e sistemas. Essa colocação permite ao homem uma contribuição direta na manutenção da postura corporal, por meio da atividade motora, pois o músculo esquelético é capaz de produzir uma tensão no tecido muscular, gerada e levada às demais estruturas ósseas ${ }^{8}$.

Para uma imagem corporal adequada ser alcançada é imprescindível que ambos os sistemas neural e musculoesquelético estejam preservados, pois o controle postural é altamente influenciado por parte desses sistemas, em razão do conjunto de dados sensoriais adquiridos para verificar o posicionamento e a direção do movimento que o corpo executa no espaço ${ }^{9}$.

A postura ideal é aquela que conduz todo o corpo a um alinhamento considerado padrão, correto e exemplar, que visa depositar sob cada articulação o mínimo de sobrecarga e estresse possível, com o propósito de promover equilíbrio às posições de diversas articulações do corpo ${ }^{10}$.

A complexidade do controle motor é o alicerce da postura corporal. Essa situação é determinada pela descrição do equilíbrio que uma postura ereta exige, por esse motivo, o corpo se torna responsável por gerenciar um autocontrole de movimentos que permite uma respeitável investigação da biomecânica, cuja finalidade é identificar os desvios para uma preventiva intervenção na má postura ${ }^{11}$.

No que se refere às alterações posturais, o desalinhamento biomecânico corporal colabora na realização do exame ortostático postural visual, em que marcadores são utilizados e posicionados nos pontos anatômicos de acordo com o padrão de vista escolhido para ser observado. A avaliação tende a ser realizada nos planos frontal anterior e posterior, e ainda, sagital lateral direito e esquerdo. Também é preciso considerar que as marcações devem estar em conformidade com o alinhamento e nivelamento da superfície corporal do paciente ${ }^{12}$.

No plano frontal, em vista anterior, a cabeça, o pescoço, as clavículas, os ombros, os cotovelos, o tórax, o tronco, as cristas ilíacas, as espinhas ilíacas ântero-superiores (EIAS) e a posição patelar devem ser observados, de modo que seja possível reconhecer o alinhamento. $\mathrm{Na}$ visualização posterior, os ombros juntamente com as escápulas são analisados de forma simultânea, favorecendo a percepção de desvios relacionados às curvaturas da coluna lombar e torácica. Já nos membros inferiores, as espinhas ilíacas póstero-superiores, fossa poplítea e tornozelo são observados ${ }^{10}$.

$\mathrm{Na}$ vista lateral do plano sagital, a anteriorização ou posteriorização do ombro é averiguada, bem como a inclinação anterior ou posterior existente na pelve. $\mathrm{O}$ eixo do joelho deve ser observado para comprovar a presença de uma hiperextensão ou flexão. $\mathrm{O}$ arco longitudinal dos pés também é considerado importante para a análise, visto que as alterações ortopédicas na articulação do tornozelo são as mais persistentes características de pacientes com espinha bífida aberta $^{10}$.

A avaliação postural de crianças com MMC tem em si a finalidade de averiguar a veracidade dos aspectos físicos, sobretudo dos problemas relacionados a déficits neuromusculares e sensório-motores. Nesse sentido, é importante revelar que o pesquisador envolvido com o estudo, sendo ele profissional de saúde, deve ainda tornar claro e nortear os pais ou responsáveis sobre qualquer dúvida que venha a surgir no que se refere a aptidão e independência funcional da criança ${ }^{1}$.

Os critérios para uma avaliação satisfatória dependem bastante das alterações que ocorrem no sistema muscular, pois estabelecer quais são os desequilíbrios existentes antecedem qualquer conduta que pretenda corrigir as mudanças posturais ${ }^{13}$.

Deste modo, o propósito deste trabalho é identificar as possíveis alterações posturais de crianças com disrafismo espinhal e correlacioná-las com os níveis de lesão medular congênita.

\section{MATERIAL E MÉTODO}

Tendo em vista promover uma melhor captação acerca da temática, a presente pesquisa foi desenvolvida de maneira clara, com conteúdo esquemático e conciso.

Para Moreira ${ }^{14} \mathrm{o}$ estudo de revisão é permanentemente composto por um conjunto de esclarecimentos reunidos em uma categoria que vise análise e desenvolvimento.

As bases de dados que foram usadas correspondem a Literatura Latino-Americana e do Caribe em Ciências da Saúde (LILACS), Scientific Electronic Library Online (SCIELO) e acervos de bibliotecas virtuais.

O vocabulário Descritores em Ciências da Saúde (DeCS) da Biblioteca Virtual em Saúde (BVS) foi utilizado para selecionar os artigos e as demais explorações envolvidas no referido estudo, sendo titulados com temática pertinente, integrando diversas áreas da fisioterapia, com publicação entre os anos de 2007 e 2017.

Os descritores determinados para servir de referência foram: disrafismo espinhal, postura e lesão medular congênita. Critérios de inclusão foram estabelecidos para artigos completos, gratuitos e pagos, de revisões bibliográficas, recursos experimentais e relato de casos, nos idiomas português e inglês. Foram obtidos como critérios de exclusão: artigos incompletos, projetos em edição, monografias, dissertações e teses, ou qualquer outro contexto discordante do assunto proposto.

A planificação para esta revisão foi iniciada no mês de maio, a partir da problemática indagada pelos autores da pesquisa, cujo interesse foi averiguar quais são as alterações de ordem postural que a patologia apresenta segundo o nível de comprometimento motor.

\section{RESULTADOS}

Considerando as informações obtidas acerca dos níveis de lesão medular congênita, é importante esclarecer as suas respectivas categorias juntamente com os déficits motores que 
a patologia exibe em sua particularidade.

A tabela abaixo (Tabela 1) mostra informações relacionadas aos artigos selecionados para uso na discussão, de igual valor, com instruções referentes ao nome dos autores envolvidos, ano de publicação, tipologia abordada no estudo e resultados.

Tabela 1. Relação dos artigos selecionados para análise por descrição de autor, ano de publicação, tipo de estudo e resultados

\begin{tabular}{|c|c|c|c|}
\hline Autor & Ano & Tipo de Estudo & Resultados \\
\hline Brandão et al. $^{4}$ & 2009 & Retrospectivo & $\begin{array}{l}\text { Escoliose e cifose; } \\
\text { contraturas no quadril e } \\
\text { joelho; luxação do quadril; } \\
\text { fraturas; escaras e úlceras } \\
\text { de pressão. }\end{array}$ \\
\hline Rocco et al. ${ }^{5}$ & 2007 & $\begin{array}{l}\text { Clínico } \\
\text { retrospectivo }\end{array}$ & $\begin{array}{l}\text { Paralisia flácida; fraqueza } \\
\text { muscular; hipersensibili- } \\
\text { dade abaixo da lesão; } \\
\text { escoliose; pé } \\
\text { congênito. }\end{array}$ \\
\hline $\begin{array}{l}\text { Cipriano e } \\
\text { Queiroz }^{15}\end{array}$ & 2008 & $\begin{array}{l}\text { Descritivo, com } \\
\text { abordagem } \\
\text { qualitativa }\end{array}$ & $\begin{array}{ll}\text { Carência física de } \\
\text { estímulos e ausência de } \\
\text { reações reflexas; atraso } \\
\text { na aprendizagem e } \\
\text { intelecto prejudicado. }\end{array}$ \\
\hline $\begin{array}{l}\text { Christofoletti et } \\
\text { al. }^{16}\end{array}$ & 2007 & $\begin{array}{l}\text { Delineamento de } \\
\text { relato de casos }\end{array}$ & \begin{tabular}{lr}
\multicolumn{2}{l}{ Comprometimento } \\
sensorial e & motor nas \\
extremidades & inferiores; \\
hipercifose & e \\
hiperescoliose; r paresia \\
dos músculos & flexores \\
plantares. &
\end{tabular} \\
\hline Collange et al. ${ }^{17}$ & 2008 & $\begin{array}{l}\text { Transversal } \\
\text { prospectivo }\end{array}$ & $\begin{array}{l}\text { Paralisia flácida nos } \\
\text { quadris; } \\
\text { alteração de tônus e força } \\
\text { muscular. }\end{array}$ \\
\hline Mota et al. ${ }^{18}$ & 2014 & Caso clínico & $\begin{array}{l}\text { Paralisia na musculatura } \\
\text { flexora dos membros } \\
\text { inferiores; } \\
\text { muscular de membeza } \\
\text { superiores; déficit de } \\
\text { equilíbrio estático. }\end{array}$ \\
\hline
\end{tabular}

*Fonte: Dados da pesquisa, 2017

\section{DISCUSSÃO}

Estudo realizado de forma descritiva por Cipriano e Queiroz ${ }^{15}$ constatou que os níveis de lesão medular podem ser classificados em quatro divisões, de ordem neurológica, sendo cognitivos e motores. Perceberam ainda, que a carência física de estímulos e a ausência de reações reflexas são altamente perceptíveis e capazes de comprometer o desenvolvimento neuromotor da criança.

Em concordância com os autores citados anteriormente, Christofoletti et al. ${ }^{16}$ descreveram as possíveis alterações motoras que retratam o perfil característico de crianças com disrafismo espinhal. Alterações cognitivas, sensoriais e motoras também se destacam em sua pesquisa. A dificuldade para manter-se em postura bípede ou equilíbrio estático, bem como a inabilidade para executar a marcha, desequilíbrios osteomioarticulares, fraqueza muscular em extremidades, deformidades ósseas, contraturas, instabilidade postural e outras queixas clínicas são fatores que interferem de modo direto na qualidade de vida.

No que diz respeito ao dano medular Rocco et al. ${ }^{5}$ descreveram os traços clínicos de acordo com a altura da lesão. Na lesão motora torácica a paralisia flácida é total. Dessa forma, a criança acometida não é capaz de apresentar sensibilidade ou qualquer funcionalidade na musculatura dos membros inferiores.

Há outro nível de comprometimento situado na altura das vértebras lombares L1-L3, classificado como lombar alto. Nessa situação, a sensibilidade localizada abaixo dos quadris é detectável, assim como, alguns músculos responsáveis pela função de flexionar e aduzir o quadril, estender o joelho ou controlar o tronco encontram-se preservados ${ }^{5}$.

$\mathrm{Na}$ região lombar baixa, as vértebras L4-L5 lesionadas, apresentam um bom prognóstico para a marcha devido à musculatura funcionante. E no último nível motor, classificado como sacral, o diferencial está na área acometida, pois a estrutura sacral, embora agredida, permite ao indivíduo uma possibilidade ainda maior para a realização da marcha, já que a musculatura responsável para tal ação aparece conservada ${ }^{5}$.

As informações contidas em pesquisa desenvolvida por autores Brandão et $\mathrm{al}^{4}$ serviram para confirmar os resultados coletados nas demais explorações. Foi verificado que déficits estruturais e deformidades esqueléticas, tais quais: pé torto congênito e escoliose são considerados problemas de maior relevância em pacientes com espinha bífida aberta alta.

Em outro caso, de cunho mais específico, Mota et al. ${ }^{18}$ relataram o estudo clínico de um paciente submetido a 10 sessões de fisioterapia motora, cujo diagnóstico cinéticofuncional foi dado a partir da avaliação física, que evidenciou paraplegia na musculatura flexora, paresia nos membros superiores e déficit de equilíbrio estático.

É válido ressaltar que todos os autores demonstraram estar de acordo com as desordens que acometem o alinhamento biomecânico dos pacientes. Ainda nessa perspectiva, segundo Collange et al. ${ }^{17}$ as crianças portadoras de MMC se caracterizam pela constante paralisia flácida nos quadris e abaixo deles. Também apresentam deformidades na coluna vertebral, alteração de tônus, fraqueza muscular e algum tipo de interferência na função dos membros superiores.

\section{CONCLUSÃO}

O estudo apresentado objetivou identificar as possíveis alterações posturais de crianças com disrafismo espinhal, correlacionando-as com os níveis de lesão funcional a partir de uma análise postural

Levando em consideração que as alterações motoras mais persistentes se enquadram na classe locomotora, é de suma importância atribuir ênfase ao recurso de avaliação postural, visto que, é um método bastante usado na ciência da reabilitação, também sendo capaz de atuar desde a atenção básica com assistência preventiva, até a fase de reparação, visando restabelecer a funcionalidade e independência da criança.

Diante da escassez acerca do conteúdo referente ao tema, este trabalho apresentou limitações no campo científico. Dessa forma, o presente estudo serviu como fonte de auxílio para todos na grande busca do saber, propiciando novas investigações na área escolhida, com interesse em futuros projetos, de ordem prática.

\section{REFERÊNCIAS}

1. Netto JM, Bastos NA, Figueiredo AA, Pérez LM. Spinal dysraphism: a neurosurgical review for the urologist. Rev Urol. 2009;11(2):71-81.

2. Pinheiro M. Fundamentos de neuropsicologia - o desenvolvimento cerebral da criança. In: Vita et Sanitas, Trindade/Go. 2007;1(1).

3. Souza ASR, Arruda TAM, Amorim MMR, Pacheco AJC. Espinha Bífida: conceitos atuais. Femina. 2007; 35(7):455-62.

4. Brandão AD, Fujisawa DS, Cardoso JR. Características de crianças com mielomeningocele: implicações para a fisioterapia. Fisioter Mov. 2009; 22(1):69-75.

5. Rocco FM, Saito ET, Fernandes AC. Perfil dos pacientes com mielomeningocele da Associação de Assistência à Criança Deficiente (AACD) em São Paulo - SP, Brasil. Acta Fisiatr. 2007;14(3):130:3. 
6. Peggy AH. Exercícios terapêuticos para lesões musculoesqueléticas. Manole: Barueri; 2015.

7. Floyd RT. Manual de cinesiologia estrutural. Manole: Barueri; 2011.

8. Hamill J. Bases biomecânicas do movimento humano. Manole: Barueri. 2016.

9. Shumway-Cook A, Woollacott MH. Controle motor: teoria e aplicações práticas. Manole: São Paulo; 2010.

10. Magee DJ. Avaliação musculoesquelética. Manole: São Paulo; 2010.

11. Neves MMF, Leite JMRS. Avaliação postural em crianças do ensino fundamental. R bras ci Saúde. 2016; 20(4):285-92.

12. Döhnert MB, Tomasi E. Validity of computed photogrammetry for detecting idiopathic scoliosis in adolescents. Rev bras fisioter. 2008;12(4):290-7.

13. Kisner C, Colby LA. Exercícios terapêuticos: fundamentos e técnicas. Manole: Barueri. 2009.

14. Moreira W. Revisão de literatura e desenvolvimento científico: conceitos e estratégias para confecção. Janus. 2004;1(1):19-30.

15. Cipriano MAB, Queiroz MVO. Cuidado com a criança portadora de mielomeningocele: vivência da família. Rev. Rene. 2008;9(4):72-81.

16. Christofoletti G, Bela GP, Turolla RC, Serradilha S, Oliani MM, Quadros JAC. Alterações motoras e sensoriais na mielomeningocele: relato de três casos. Saúde Rev. 2007; 9(22):53-7.

17. Collange LA, Franco RC, Esteves RN, Collange NZ. Desempenho funcional de crianças com mielomeningocele. Fisioter Pesq. 2008;15(1):58-63.

18. Mota MN, Oliveira AV, Silva AJ, Rocha ER, Maia DC, Santana LS et al. Tratamento fisioterapêutico na criança com mielomeningocele: estudo de caso. Sempesq. $2014 ; 16$

\section{CONFLITO DE INTERESSES}

Os autores declaram não haver conflitos de interesse.

\section{AUTOR PARA CORRESPONDÊNCIA}

Thaynara do Monte Mélo

mmelothaynara@gmail.com

Submetido em 06/12/2017

Aceito em 09/01/2018 